

\section{CONTENTS}

Page

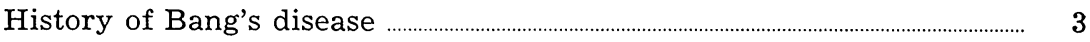

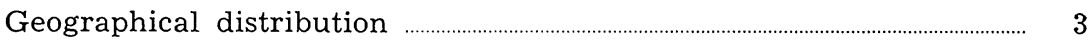

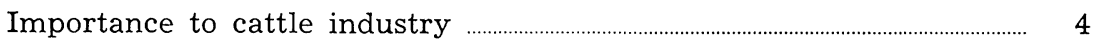

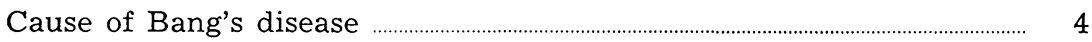

Method of development …….......................................................................................... $\quad 7$

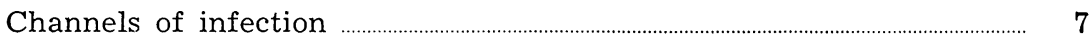

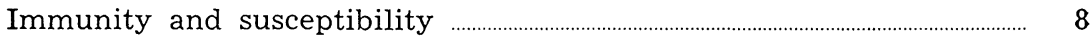

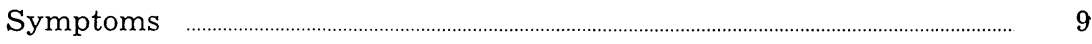

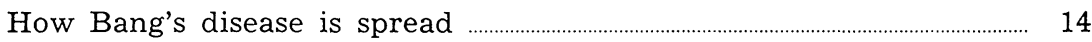

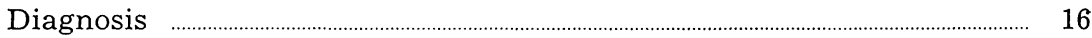

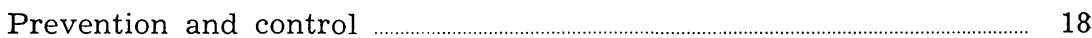

Abortions in a Bang's disease-free herd ................................................................ 27

The problem of Trichomoniasis …………........................................................................... 27

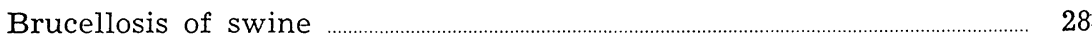

Brucellosis of sheep ................................................................................................................... 28

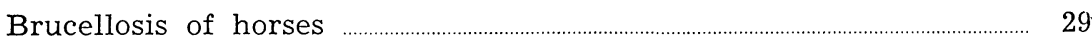

Relation of brucellosis to human health …......................................................... 30

The prevention and control of Bang's disease ........................................................ 31

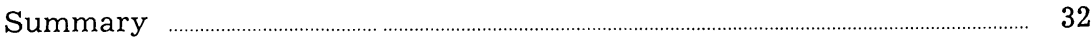




\title{
Brucellosis or Bang's Disease of Farm Animals ${ }^{1}$
}

\author{
C. P. Fitch ${ }^{2}$ AND W. L. Boyd
}

$\mathrm{T}$ HE DISEASE known variously as Brucellosis of cattle, Bang's disease, infectious abortion, contagious abortion, slinking, or dropping of calves is infectious. Abortions resulting from injuries or causes other than germs are very uncommon. "Abortion" means the birth or expulsion of an immature fetus, and this is one of the most prominent symptoms of this complex disease. "Sterility" (failure to breed) very often follows infection with the germs causing abortion. Retained placenta is also usually closely associated with abortion infection, and the premature expulsion of a living fetus (premature birth), which usually dies, is most often due to the abortion germ, Brucella abortus. Approximately 85 per cent of all abortions are due to this germ.

Diseases of calves, such as white scours and calf pneumonia, although they are not due to the same germ that causes abortion, are often found in a herd in which the adult animals are harboring the abortion infection. Diseases of calves may occur, however, entirely independent of abortion infection.

To sum up, Bang's disease or bovine infectious abortion is widespread. Its most pronounced symptom is the birth of a dead fetus before time. Sterility,

'Accepted for publication February 23, 1940. in pied January, 1940, while manuscript was
preparation. or failure to breed, and mastitis or garget are commonly associated with abortion.

\section{HISTORY OF BANG'S DISEASE}

Contagious abortion has been recorded since early times. In Germany the disease seems to have existed in a severe form in the latter part of the Eighteenth Century. Among the early investigations as to the nature of the infection were those of Nocard in France in 1885; the Highland Agricultural Society of Scotland in 1886; Bang and Stribolt in Denmark in 1897; and the Departmental Committee of the Bureau of Agriculture and Fisheries of Great Britain in 1909. In the United States, MacNeal and Kerr, in 1910, pointed out the significance of the Bang organism in relation to abortion of guinea pigs. Since then many American investigators have devoted much time and thought to the study of Bang's disease or bovine infectious abortion.

\section{GEOGRAPHICAL DISTRIBUTION}

According to available data, this disease commonly exists in all countries where cattle raising is an industry. It appears to be world-wide. In the United States the disease has spread until in many herds of either purebred or grade cattle there are animals that have been or are infected with the 
organism causing the disease. It has spread widely in the United States during the last 25 years, owing, in large measure, to the increased traffic in purebred cattle. In Minnesota approximately 12 per cent of the cattle are infected.

\section{IMPORTANCE TO CATTLE INDUSTRY}

The lack of reliable statistics concerning animal diseases in the United States makes it difficult to estimate, even approximately, the extent of the losses that must be charged against a widespread, insidious, common disease like Bang's disease. The estimates have varied from $\$ 25,000,000$ annually to much larger amounts, but most of them have been based largely on tangible or actual losses in various communities. No definite, searching, universal survey has been made that took into account the tremendous intangible losses. Consequently, all estimates may have fallen short of the actual losses.

One must not be content to figure only the probable value of a calf that was expelled dead or is weak or does not live; the shrinking of beef in the beef animal; the diminished production of milk in the dairy animal; the temporary or permanent sterility that may follow the infection; and frequently the loss of the cow herself through infection. Serious as these are, we must also take into account the enormous financial loss that the breeder of select purebred cattle may suffer because of the disease in his herd. A careful study made at the Storrs (Connecticut) Agricultural Experiment Station showed that the loss per cow in milk production alone was over $\$ 100$ annually. This was in the station herd.
Rich, studying the economic factor of abortion of cattle, found that th: total loss from abortion in the Univer. sity of Minnesota Farm herd over 29 years was $\$ 12,760$. This did not include losses from cows giving birth to dead calves over 260 days' calving period.

He also determined that the annuai loss resulting from abortion in a good commercial grade herd of 16 cows was $\$ 136$, and in a purebred herd, $\$ 486$.

Veterinarians and cattle breeders know that Bang's disease is a widespread, economically important evil. The trouble they are having because of it makes them more eager to discuss it than any other infectious disease of cattle, and they know from general observations and special studies that it is more widespread and more common than it was some years ago. It will continue to spread and become more common unless a real fight is made to control and check it.

\section{CAUSE OF BANG'S DISEASE}

Bang's disease in cattle is caused by a very small, short, oval-shaped germ, so small, in fact, that thousands of them piled one on top of the other cannot be seen with the unaided eye. In order to determine their size and shape they must ba viewed through $a$. microscope. This organism, now called Brucella abortus, was first described as the cause of contagious abortion in cattle by Professor Bernhard Bang of Denmark, and for this reason this type of abortion is called Bang's disease (fig. 1).

The germ causing Bang's disease may be found in the udder, the pregnant uterus, and in the discharges from the vagina of cows a short time after! aborting or giving birth to a full-term calf. The average length of time that 


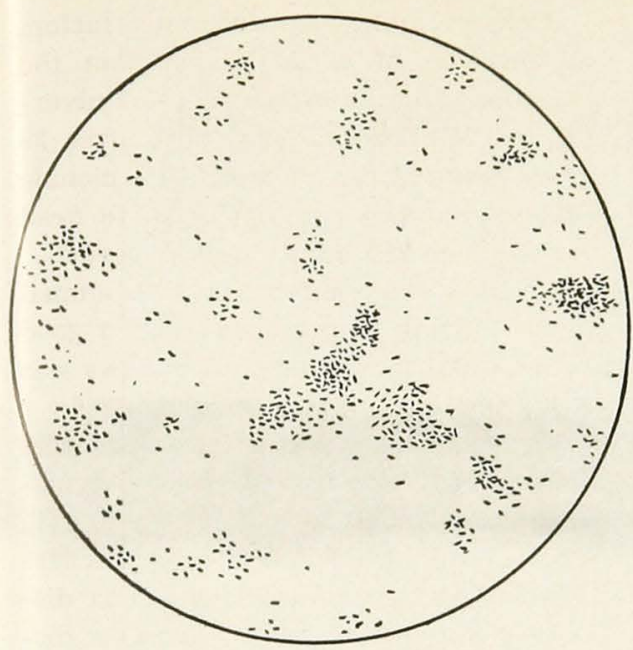

Fig. 1. Brucella Abortus, the Germ Causing Contagious Abortion, Magnified 700 Times

this germ is found in the vaginal discharges is two to three weeks after calving or aborting. During this period a cow is especially dangerous as a spreader of disease to other cows. The abortion bacteria are found in the milk and the udders of cows that have aborted and, in certain instances, in the milk of those that have not aborted. Many of these cows become permanent carriers of the Bang organism in their udders, and it is shed continually in their milk. The germ may be found also in the bodies of aborted fetuses and full-term calves.

This organism does not, as a rule, live long in pastures or barnyards and is killed in four to five hours when exposed to direct sunlight. When protected from the air and the effects of drying and sunlight, as in manure, it will survive for many days. A 21/2 per cent solution of cresol will destroy the organism in 15 minutes, and if heated to $60^{\circ}$ Centigrade or $140^{\circ}$ Fahrenheit, it will also be killed in 15 minutes.

It has been estimated by various authorities that 85 per cent of the abortions in cattle are due to Bang's disease. The other 15 per cent of abortions are due to different causes such as infections with other bacteria or protozoa, eating poisonous plants, violent physical injury to the pregnant mother, or improper nutrition. Another type of infectious abortion, resembling Bang's disease in that a number of cows in the same herd become infected and abort, is an infection caused by a germ known as Vibrio fetus. This in-
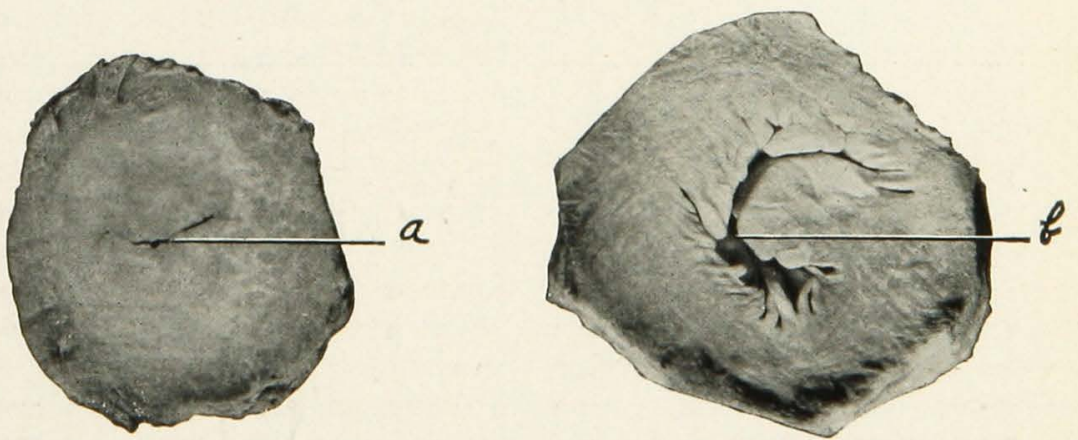

Fig. 2. A. Cross-Section of Cervix or Neck of Womb Showing Normal small Passage from Vagina to Womb B. Same Passage near the Vagina

This opening is completely closed only when the animal is pregnant, and contrary to popular opinion seldom requires "opening" for the animal to breed. 


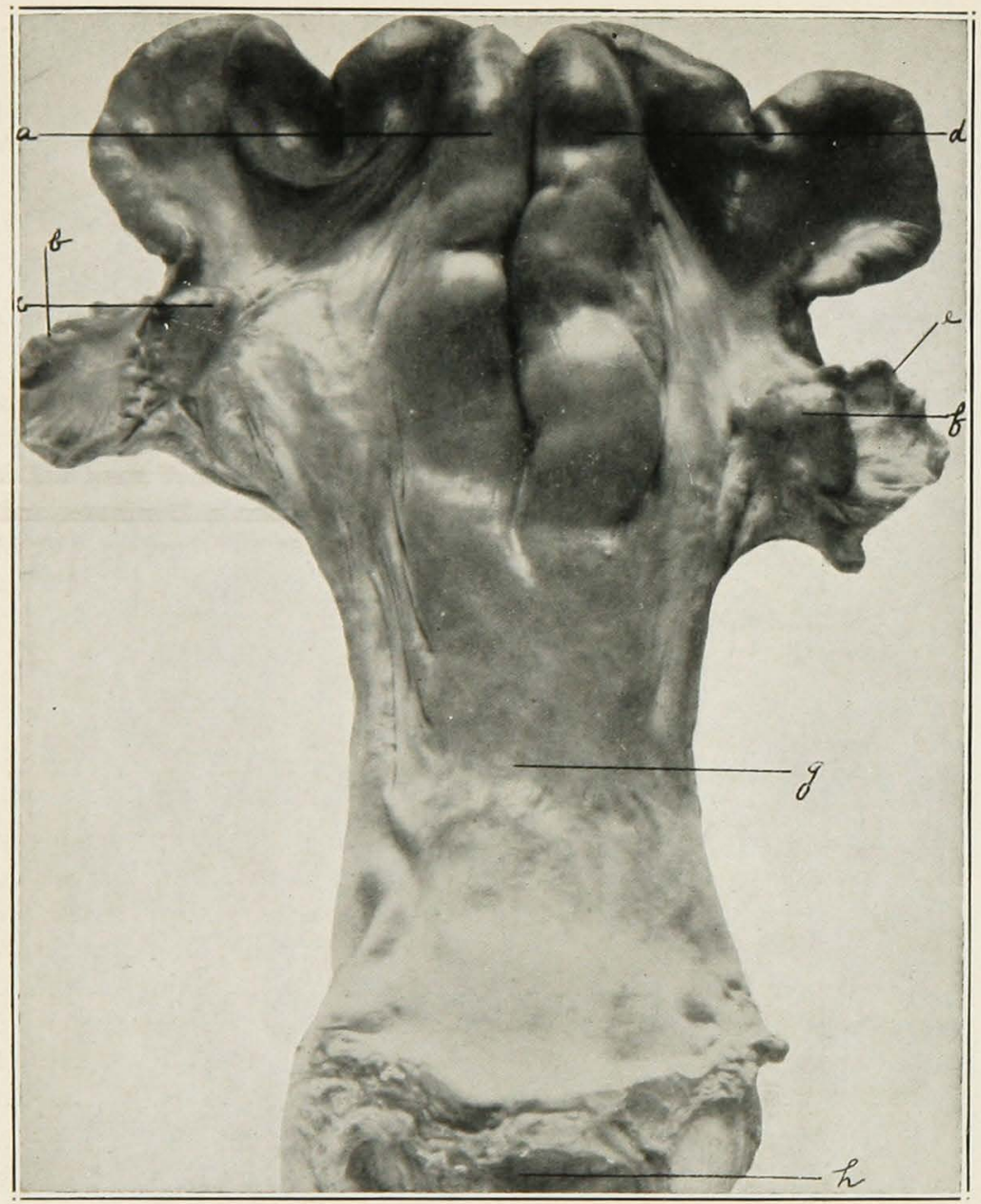

Fig. 3. Normal or Healthy Bovine Uterus

a. Left horn of uterus; b. Left Fallopian tube; c. Left ovary; d. Right horn of uterus; e. Right Fallopian tube; f. Right ovary; g. Body of uterus; and h. Location of opening of cervix.

fection differs in many respects from Bang's disease and has been found in only a few herds in Minnesota. During recent years abortions have been caused by a protozoan parasite called Trichomonas fetus. This particular organism affects bulls as well as cows and is mainly transmitted at service.

Brucella abortus has some very close relatives in similar bacteria causing abortion in sheep, goats, and swine, and is often found in fistula and poll evil of horses. Humans also have contracted a disease called "undulant fever" from drinking infected cow's milk or handling infected swine carcasses. This entire group of diseases is referred to as "Brucellosis." 


\section{METHOD OF DEVELOPMENT}

Abortion, which is the most prominent symptom of Brucellosis of cattle (Bang's disease, contagious abortion of cattle) is produced by an inflammation of the cotyledons or so-called "buttons" which unite the inner lining of the uterus (womb) of the mother and the coverings or membranes which envelop the fetus (calf). The severity and extent of the inflammation of the cotyledons and other portions of the membranes determine largely whether or not a pregnancy will terminate in a full-time or a premature birth, or in abortion. If the involvement of the attachment between the maternal and fetal membranes has been severe and has occurred during early pregnancy, it often results in the expulsion of a dead fetus, while a lesser involvement may result in the birth of a live, though greatly weakened calf. Such calves frequently die shortly after birth. If they live, they offer little resistance to the germs that cause white scours and pneumonia, the common diseases of newborn and young calves. Infected or diseased cows may produce strong and vigorous calves and promptly expel the fetal membranes (afterbirth), but they may still be a grave source of danger by spreading the germs through the fetal fluids during the act of birth and later through discharges from the genital tract.

\section{CHANNELS OF INFECTION}

The germ usually enters the cow's body through the digestive tract. The vagina does not seem to be an im-

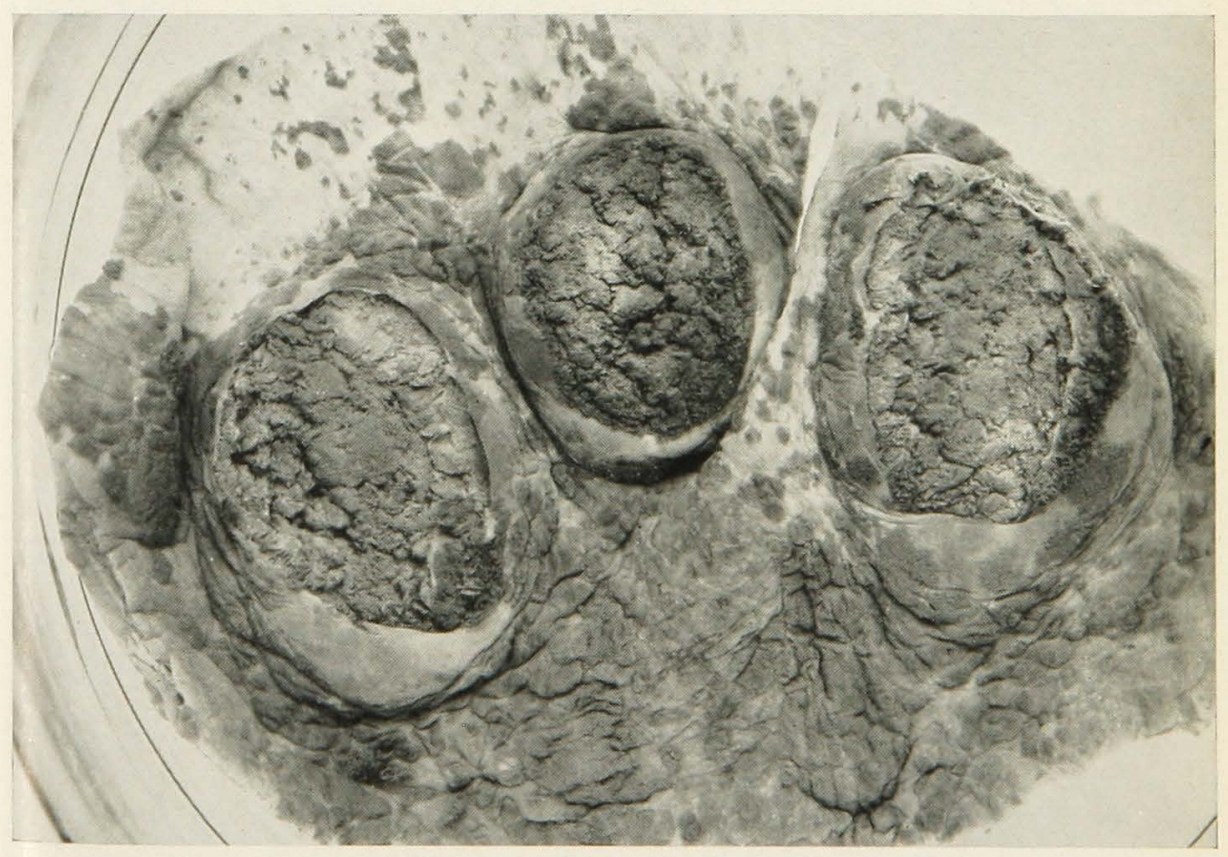

Fig. 4. Part of the Fetal Membranes Showing Cotyledons or "Buttons" Extensively Diseased as a Result of Infection with the Abortion Organism 
portant channel through which the germ enters the body. Infection by way of the digestive tract usually occurs by the animal's consuming food contaminated by the genital discharges of an infected animal. Also, animals are accustomed to lick themselves or other cattle, and in this manner virulent abortion germs may enter the body. In recent years, it has been shown that cattle can be infected readily by placing the germs in the eye. The significance of the eye as an avenue of natural infection is not known, but it may be of some importance. It has been shown also that the germs will enter the body of laboratory animals and cattle through the unbroken skin. The importance of this method has not been determined, but it suggests another channel through which animals may contract the disease.

The part played by the bull in the transmission of the disease has long been a matter of much dispute. Experimental evidence shows a possibility that the bull may transmit the disease by being actively infected and discharging the germ in the semen. There is also experimental evidence indicating that there is a possibility of the germs entering the udder of a cow through the teat canal.

Calves do not usually harbor infection from birth, nor do they usually become permanently infected with the germ through nursing mothers harboring abortion bacilli in their udders, provided nursing is discontinued early in the life of the calf. Experimental evidence has shown that calves fed on milk containing abortion organisms may eliminate living abortion bacilli in the feces. This elimination must be considered an important factor in the spread of the disease. Heifers that have begun to come in heat should be carefully kept from all material contaminated with abortion germs.

\section{IMMUNITY AND SUSCEPTIBILITY}

Calves under six months are especially resistant and might be said to be immune to Bang's disease. Sometimes they will give a positive blood test, but as a rule they do not become permanently infected. Young heifers in their first or second pregnancies are particularly susceptible to this disease and, if exposed to infection usually contract it and abort. Older cows also contract this disease although not so readily as heifers. Bulls are less susceptible but at times will give a positive blood test. Occasionally there will be a sudden inflammation in one or both testicles of the male caused by the abortion bacillus, and there may be a temporary, reduced fertility (fig. 10). Frequently the animals will become permanent nonbreeders. No one breed or type of cattle is any more resistant to this infection than another, and the disease is no more prevalent in one breed than in another.

Not all animals react alike when exposed to Bang's disease. There are varying degrees of susceptibility. If infection is introduced into a clean herd, the females of breeding age may be grouped into distinct classes depending upon their natural resistance to Bang's disease. Some animals appear to have resistance or immunity against the disease. These animals, however, are relatively few in number.

One group will become infected, some of them will abort, and most o! them will be spreaders of the diseasc through their milk and vaginal dis- 


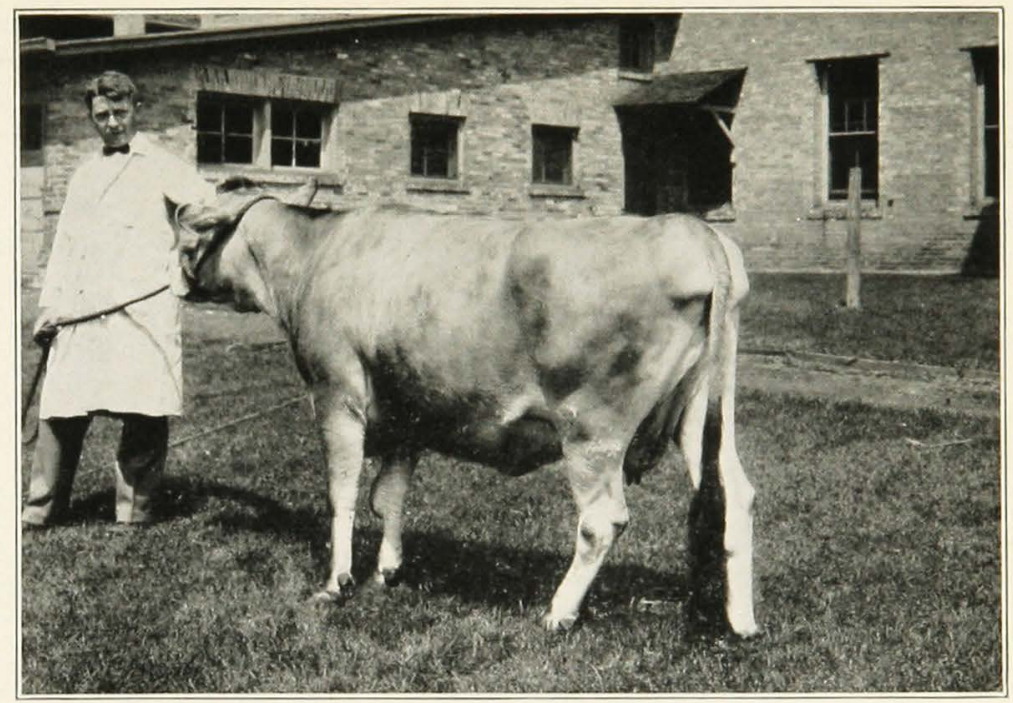

Fig. 5. This Cow Aborted Six times and Had One Living Calf at Full term, as a termination of Seven Pregnancies

charges. These cows may recover in a year or more, occasionally in a few months, and cease reacting to the agglutination test and spreading bacteria. This group is also small because most cows that acquire Bang's disease after they reach breeding age do not recover and may be spreaders of infection as long as they live. Two degrees of resistance are found among cattle that remain infected. Some of them will become normal breeders and to all appearances will be normal cows. These animals are, however, still spreaders of Bang's disease. Many cattle belong in this group. However, a larger number of infected animals become unproductive breeders and abort repeatedly (fig. 5) or fail to conceive when rebred and are a total loss as far as reproduction is concerned.

Resistance or immunity to this disease by some animals is evident under special conditions. This tendency toward immunity has stimulated at- tempts to produce a satisfactory artificial immunity. The hope of controlling Bang's disease by vaccination has not yet been realized. The only method that has shown much promise of success consists in vaccination of young calves with living abortion germs of reduced virulence. Experimental evidence and experience have shown that vaccination frequently reduces the percentage of abortions in a herd. However, the resistance resulting from vaccination is not consistent, and the experiments have not been carried on long enough to justify recommending calfhood vaccination generally as a method of combating Bang's disease.

\section{SYMPTOMS}

Brucellosis, from the standpoint of frequency of occurrence and economics, is far more important in cattle than in other farm animals. Next to cattle the disease is encountered most frequently 
in swine. Horses are probably more susceptible than sheep although this contention has not definitely been determined.

\section{Abortion}

The symptoms of Brucellosis among farm animals, with the exception of the horse, are quite similar. The localization of the causative organism in the animal body largely determines the symptoms of the disease. Brucella abortus or the Bang germ, when present in cattle, swine, and sheep, selects the pregnant uterus (womb) as the place best adapted for its growth and multiplication. Therefore, the most striking symptom, although not always a constant one, consists of the expulsion of the fetus or fetuses at various stages of their development.

Although the organism selects the pregnant uterus of the cow, ewe, or sow as the place most favorable for its development, the same general conditions do not apply to the mare. Abortions occurring in mares are an important problem, but seldom are they caused by the activities of Brucella abortus. Once the germ invades the horse's body, it attacks adult structures such as muscles, tendons, and joints.

With this understanding, one can readily realize that the stallion or gelding is almost, if not fully, as susceptible to the disease as is the mare. Such characteristics show a marked dissimilarity of the disease in the horse as compared with the characteristics manifested in cattle, sheep, and swine. The rather common diseased conditions of horses known as poll evil and fistula of the withers are now known to be caused frequently either directly or indirectly by Brucella organisms. Involvement of joints and other parts of the body may occur. Recent studies of the horse indicate that the disease may cause systemic disturbances characterized by an elevation in temperature and general dullness.

Systemic disturbances in the cow previous to abortion seldom occur. Heifers and frequently mature or even. aged cows will, by developing the same symptoms characteristic of an approaching parturition (normal calving), forecast an approaching abortion. Again, the presence of a dead fetus in the gutter, stall, pen, or pasture may be the first evidence of the disease. Abortion in cattle as the result of Brucella infection occurs mainly between the fifth and seventh month of the gestation period. Abortions at an earlier date are frequently caused by other bacteria or occasionally by unknown agents.

\section{Fetal Membranes}

When the abortion takes place up to four months after breeding, the fetal membranes (afterbirth) are expelled with the fetus. Abortions occurring later are frequently characterized by retention of the fetal membranes. Failure of the cow to release the fetal membranes following an abortion 0 : when giving birth to a full-time cal: is an indication, though not a constant or positive one, that she is affected with Bang's disease. Failure of the cow to clean or release her fetal membranes is a highly important problem. No only does it delay milk production anc! encourage mastitis (garget), but i: may even lead to death as a result of: a generalized infection. Retention o the afterbirth usually means that the cow will have difficulty in becoming: pregnant again. Lowered milk production resulting from premature lacta- 
tion and a high incidence of infertility (breeding troubles) are also symptoms of the disease.

\section{Symptoms in Other Animals}

The symptoms in ewes and sows are similar to those occurring in cows. Brucellosis when present in the bull, boar, and ram manifests itself by producing enlargement of one or both testicles as the result of inflammation. Males thus affected often lose their ability to breed successfully.

The symptoms given, although characteristic of Brucellosis, cannot be regarded or accepted as being always definite and sure signs. These same symptoms may occur from certain other causes, particularly bacterial. Seldom, though, do abortions produced by causes other than the Bang germ rival Bang's disease in frequency or extent of territory involved. A disease presenting a variety of symptoms as de- scribed above is difficult, if not impossible, to recognize correctly on the basis of symptoms alone. In addition, the recognition of the disease is made more difficult because many infected cows do not in any way show visible signs of the disease.

Other symptoms consist of enlargement of the joints, especially the knee joints (hygroma). Swelling of the knees may occur from other causes, but they are far from common in Bang-free herds (fig. 6).

Retention of the fetal membranes following the delivery of calves at term is an unusual occurrence in herds free of Bang's disease. Cows that clean within a few hours following the birth of their calves are vastly more profitable than those that fail to clean. Breeders of cattle, both dairy and beef, are fully cognizant of this fact and are much concerned in obtaining and maintaining herds free from Bang's disease.

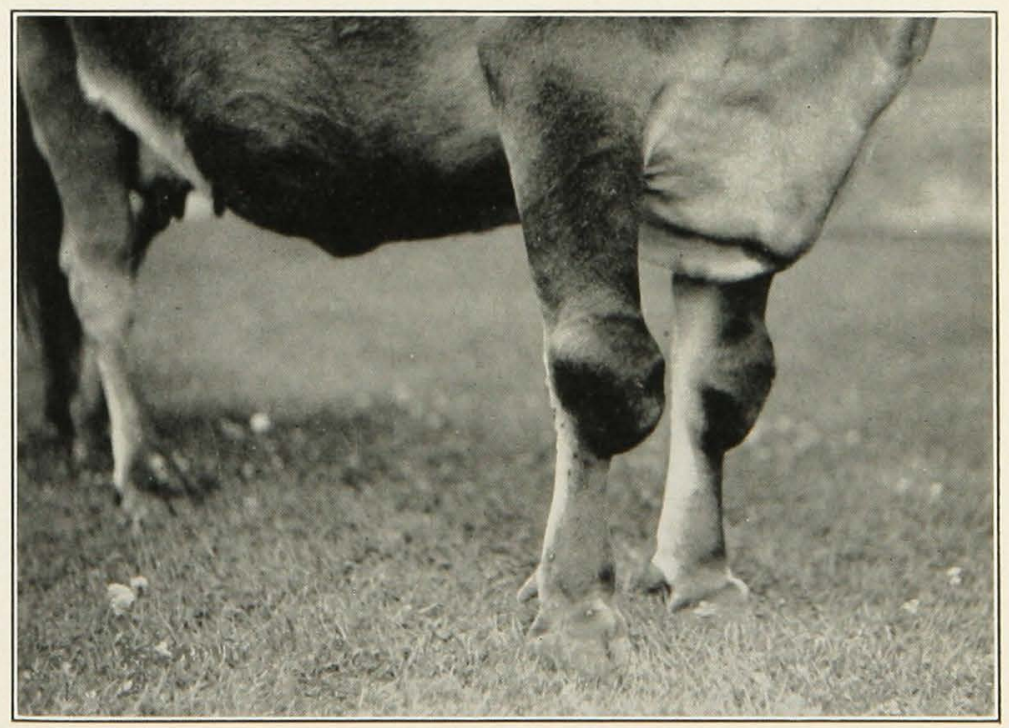

Fig. 6. Big Knees of Cattle are Often Associated With Brucella Abortus Infection 


\section{Breeding Trouble}

The incidence of infertility or breeding troubles is higher in Bang-infected than Bang-free herds. Control of the disease, therefore, is highly desirable because it not only enables the owner to regularly execute his breeding plans but also insures a larger number of healthy young. This fact applies not only to cattle but also to sheep and swine as well. Female cattle, swine, and probably sheep when attacked by Bang's disease suffer from inflammation of various parts of their reproduc- tive tracts. These changes are often chronic in nature and may exist for weeks and even months before the animals are again ready to be bred.

The pregnant uterus and udder of the cow have long been known to provide suitable living conditions for the Bang germ. Though the germs usually leave the uterus soon after abortion, they may remain in residence for a long period of time. The mammary gland or udder acts as a reservoir for the germ and, though mastitis or garget is not often directly due to the activity of these germs, garget ap-

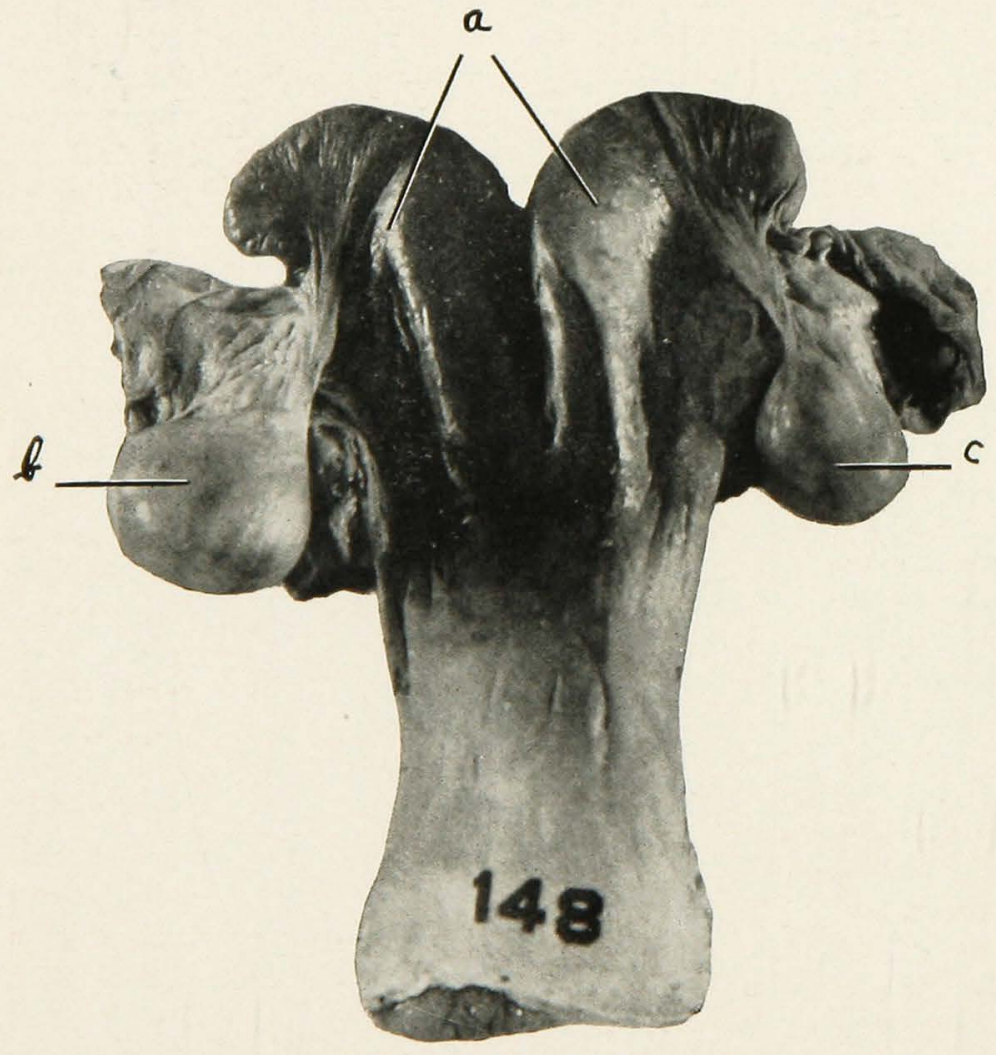

Fig. 7. Uterus and Large Diseased Ovaries Which are CYSTIC, FROM A NON-Breeding CoW

a. Horns of uterus

b. Cystic ovary, left

c. Cystic ovary, right 


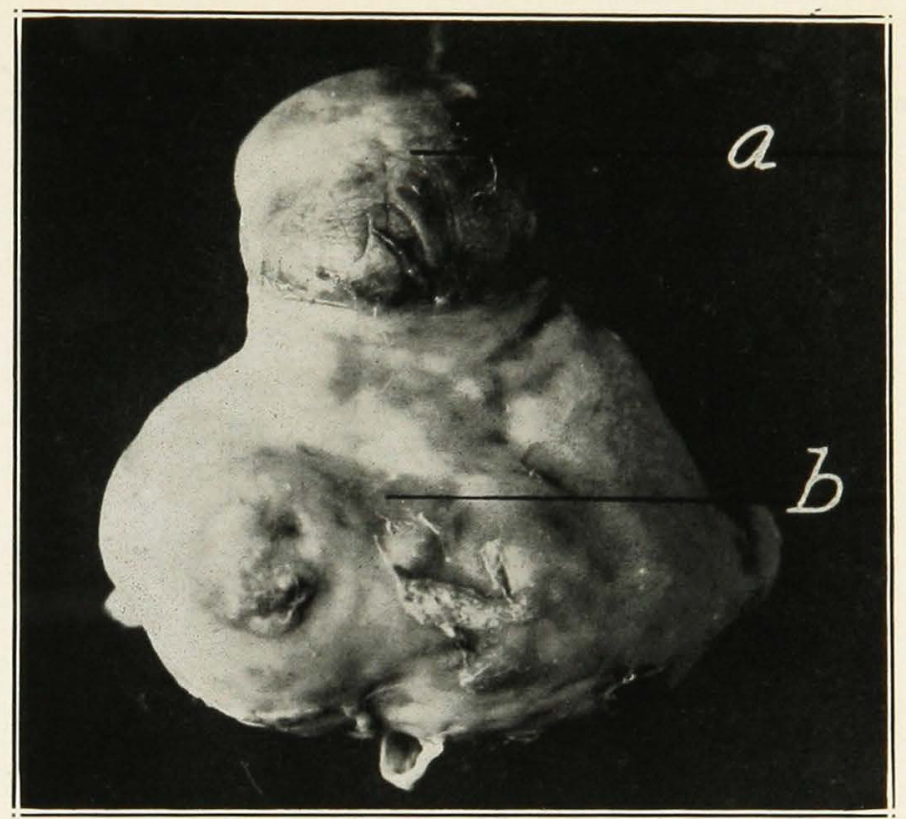

Fig. 8. Ovaries Showing a Large Retained Cotpus Luteum a. Retained yellow body or corpus luteum

b. Body of ovary

parently is less common in herds in which Bang's disease does not exist.

We said in 1936, "Cystic degeneration of the ovaries is not uncommon in aborting cows." ${ }^{3}$ This is still the case today, but it should not be considered as evidence of Brucellosis because it occurs just as frequently in cows that are free of Bang's disease. Inflammation of the breeding organs of sows infected with this disease are similar to, if not identical with, those of cattle. Cystic degeneration of the ovaries of the sow also occurs in noninfected and infected sows.

In cattle, as in other mammals, an egg bursts from the ovary and is conveyed to the uterus by the oviduct following the heat period. The union of

${ }^{3}$ Fitch, Boyd, and Bishop, "Bang's Disease of Cattle," University of Minnesota, Agricultural Extension Division Special Bulletin 28, 1936 , p. 11. the egg (the female cell) with the male germ cell results in the formation of an embryo, or young. The place left in the ovary by the rupture of the egg sac is taken by cells having a peculiar yellowish color which together make up what is termed the corpus luteum or "yellow body" (fig. 8). If the ovum (egg), which was discharged at this time, is fertilized and pregnancy results, this so-called yellow body, or corpus luteum, grows to considerable size (three quarters of an inch to an inch in diameter) and remains in the ovary until the termination of pregnancy. Following parturition, the corpus luteum is gradually absorbed. If the ovum is not fertilized, the cells of the corpus luteum begin to disappear or to be absorbed within two weeks following the heat period. 
Frequently, as a result of deranged functions of the genital organs, the corpus luteum is not absorbed or the retrogressive changes do not take place following parturition. Sometimes the corpus luteum, although pregnancy has not taken place, remains unchanged. This condition may interfere with the further ripening and escape of ova by mechanical interference and also by an internal secretion. Both of these conditions, namely, the one resulting when pregnancy has not taken place and the one occurring after pregnancy is terminated, are termed "retained corpora lutea." As a result of these retained yellow bodies the animal may fail to come in heat, often leading the breeder to suppose that the animal is pregnant or permanently sterile. A retained corpus luteum may become cystic (cavities filled with fluid develop) which interferes with the function of the ovary and results in constant or irregular heat periods. Animals thus affected imitate the male animal and are often called "bullers."

To repeat, then, the observed act of abortion is only one of the symptoms of this disease. The animal may abort unnoticed during the early stages of pregnancy, and the owner may think merely that she did not conceive at the previous service. Discharges from the vagina, especially of a brownish or yellowish color, abundant, and at first odorless, indicate infection. Failure to breed is frequently the result of an initial infection by Brucella abortus.

\section{HOW BANG'S DISEASE IS SPREAD}

The introduction of diseased females into healthy herds is the most common method of spreading the disease from one herd to another. Traffic in cattle has been an important factor in the spread of this disease into the large number of herds in which it exists at present. Owners of cattle should be exceedingly cautious in selecting animals to be added to healthy herds. Not all diseased females abort their young. The fact that a female has a normal calf is not conclusive evidence that she is free from this disease. Many cattle buyers have been misled by the appearance of a normal number of calves in ratio to the number of females in a herd from which purchases are to be made. The only reliable or practical method of selecting animals for introduction into healthy herds is the intelligent use of the agglutination blood test.

Susceptible females may contract the disease if they are housed in stalls in which animals have aborted. Common carriers (trucks and railroad cars) may be possible sources of infection unless they have been thoroughly cleaned and disinfected.

Diseased females are a constant source of danger to other animals in the herd. They are particularly dangerous at the time of calving or aborting and during the period pre.. ceding and following the expulsion of the fetus from the uterus, at which time there is a discharge from the genital organs. The contents of the uterus (fetus, fetal membranes, and fluids) contain myriads of the germs and when expelled become agents by which the disease spreads. A diseased female may give birth to a normal calf and yet be an important source of danger? to healthy animals. Experimenta! work has shown that 25 days is usually the maximum time following abortion that the germs will be spread by discharges. 
Abortion germs are commonly discharged in the milk of diseased cows. Mature animals generally do not coniract the disease from this source. However, the milk of diseased cows should be considered an infective agent. The openings in the teats of a few animals are excessively large (leakers) so that milk is more or less continuously discharged. In these cases, when the milk contains abortion germs, diseased cows may contaminate grass or other foodstuffs. Careless handling of milk, such as milking onto the floor of the barn, may provide an opportunity for the abortion germs in the milk to gain access to healthy animals.

Young calves generally are not susceptible to infection with abortion germs. It is advisable to allow the newborn calf to get the first milk (colostrum). The first milk of diseased cows can usually be fed without serious danger to a young calf although the calf should not be fed milk from diseased cows any longer than is absolutely necessary. In most cases it is possible to select healthy animals to provide milk for calf feeding. Considerable evidence indicates that some young heifers take in abortion germs with milk and retain them without showing any evidence of the disease until later. This is not, however, a common occurrence. When heifers have $r$ ached the age of sexual maturity, some of them are likely to cortract the disease if allowed to drink milk cont..ining abortion germs.

The germs taken in with the milk by yung calves are eliminated through the manure. The statement has been made frequently that heifers under six months are the safest females to add to: healthy herds. Such animals are usually safe provided they are nega- tive to the blood test and are isolated for two to three weeks, until the germs are eliminated from their bodies, before they are allowed to enter the premises used by healthy animals. The feet, legs, and abdomen of such calves should be washed with an antiseptic solution ( 2 per cent sheep dip) before they are moved to the quarters occupied by abortion-free animals.

This disease probably spreads as frequently in the pastures and paddocks as in the barns. Animals abort without giving any warning, and the fetus has been expelled before the herdsman realizes that anything is wrong with the animal. Many early abortions pass unnoticed. Pasture calving has been advocated by some persons, but it frequently is responsible for the spread of abortion disease. The use of clean maternity stalls for all calving or aborting animals is of great value in preventing spread of the disease.

The segregation of infected and healthy animals in different parts of the same barn will not prevent the spread of Bang's disease if a common pasture or paddock is used.

The bull is not a significant factor in the spread of abortion disease. It has been stated that the sire may carry the germs on his penis. This is not an important method of spread. The bull himself may become infected and eliminate the germs in his semen. When the bull is harboring abortion germs, they may be discharged into the vagina of the female at the time of service. As a rule the germs will not enter the circulating fluids (blood or lymph) of the cow's body from the vagina. The germs that enter the vagina at the time of breeding may later pass out of the genital tract and contaminate the tail and external genitals and drop onto 
grass or other foodstuffs. Other females may then take these germs into their bodies through the mouth by licking the cows or consuming foodstuffs that become contaminated in this manner. In the present state of our knowledge, the digestive tract is the chief way by which the animal becomes naturally infected with the germ.

While it is not a desirable practice, experience has shown that the breeding of healthy bulls to diseased and healthy cows rarely results in the spread of Bang's disease if the mating occurs on neutral ground, that is, ground not used by healthy or diseased animals. Certain other germ diseases of the genital organs of cattle are regularly transmitted by the bull from one cow to others through the act of service.

There are numerous other ways by which infective material may be transmitted to healthy females. These include poor drainage; contamination of barn equipment and shoes and clothing of attendants; and pastures separated by single fences. It is probable that not all of the methods of spread of this disease are understood.

When the various ways in which this infection spreads are considered, the difficulties of controlling it are realized. Preventing the spread of this disease is not easy, but experience has shown that it can be done successfully. Light, cleanliness, and ventilation are prime factors from the standpoint of control and should be observed as carefully and rigidly as possible. Taking into consideration the foregoing points, the breeder will readily appreciate the need of good stable sanitation, the proper disposal of infective material, and the danger of introducing new animals into the herd.

\section{DIAGNOSIS}

The history of abortions in a herc? may strongly indicate Bang's disease, but an absolute diagnosis of this disease cannot be made without a laboratory examination. Two facts must be remembered: (1) Some cows may never abort, yet they are dangerous spreaders of Bang's disease. (2) Some cows that are not infected abort. Since we cannot rely entirely on history and symptoms for an accurate diagnosis, and since only approximately 85 per cent of abortions are due to Bang's disease, it is far safer to have a laboratory examination made in all cases. This diagnosis may be a bacteriological examination of such material as milk, aborted fetuses, afterbirths, or vaginal discharges, or it may be a blood test.

\section{Bacteriological Examinations}

By bacteriological examinations it is possible to isolate the bacteria and to grow and study them in the laboratory. These methods are too expensive and require too much time to be adaptable for the routine diagnosis of this disease in a large number of animals. The blood test is reliable and is less expensive, more rapid, and therefore more practical for examining large numbers of cattle than the bacteriologi-. cal examination. In the past, bacteriological examinations have demonstrated the dependability of the blood test.

\section{Blood Tests}

A safe, reliable, and practical methor? of diagnosis of Brucellosis of cattle i: available in the blood test known as the agglutination test (fig. 9). This tes 
will not determine which of the diseased females will or have aborted. It will determine which are or have been harboring the Bang germ and are, consequently, possible sources of infection.

It is not claimed that the agglutination test is 100 per cent reliable, but it is sufficiently reliable to permit the successful control of Bang's disease. Animals that are tested for Bang's disease are divided into three groups: positive or reactor, (2) suspicious, (3) negative.

Positive animals are or have been harboring the germs and should be considered dangerous to other animals.

Suspicious animals are those in which a single blood test does not justify classifying them either as positive or negative. They should be retested in 30 days.
Negative animals are not at the time of the test infected with Brucella abortus, except those that have very recently contracted the disease and have not yet developed evidence of it in their blood. An occasional diseased animal will have a negative test if the blood sample is obtained either a few days before or after a calving or abortion. The explanation of this negative phase is not known, but in such cases it often causes persons to question unjustly the accuracy of the agglutination blood test. The fact that an animal has a negative test does not mean that it will remain negative because there is always danger of subsequent infection. Too much reliance should not be placed on a single negative test, especially if there is evidence of active infection in the herd or if the blood sample has been taken a few

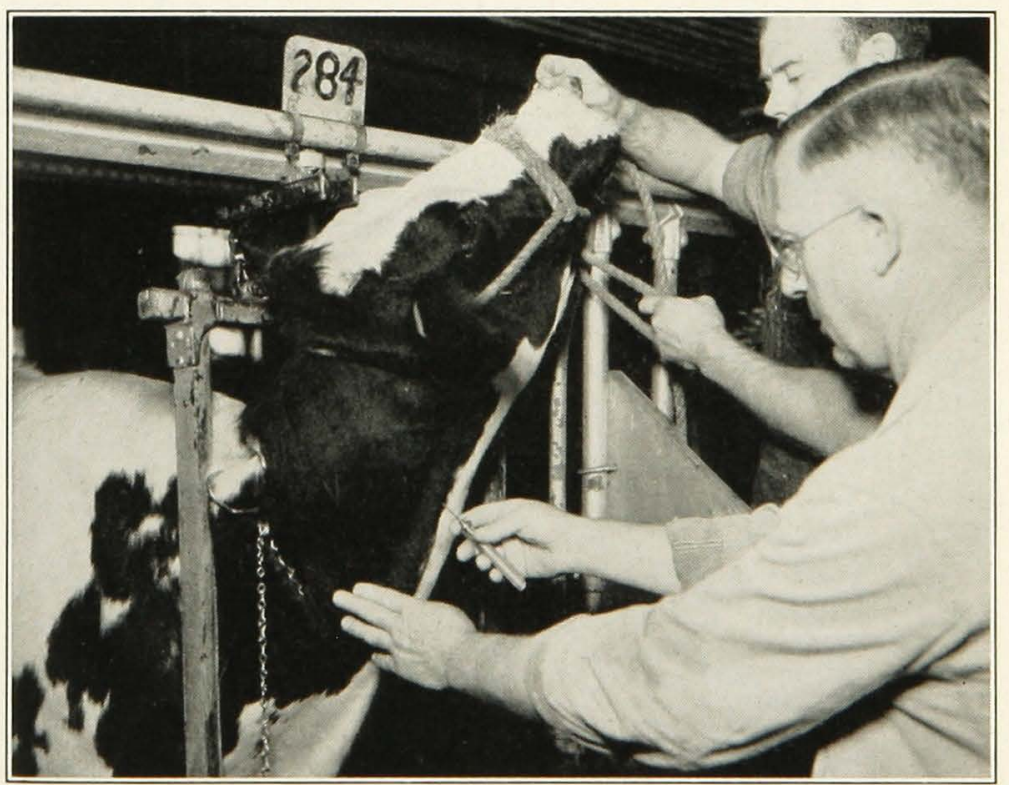

Fig. 9. Simple and Efficient Method for Collecting Biood for Testing for Bang's Disease 
days before or after a calving or abortion.

It is interesting to note the percentages of cattle tested in Minnesota which fall into the foregoing groups. Approximately 12 per cent are positive; 2 per cent are suspicious; and 86 per cent are negative. Recent extensive experiments have shown that the slight discrepancies in the results of the agglutination blood test are confined to the tests of the group of suspicious animals. Even in this group, the blood test has been perfected to a high degree of efficiency. This means that the agglutination blood test has an efficiency of more than 95 per cent, which is as near perfect as is necessary for its successful and practical use as a diagnostic method.

Two methods of conducting the agglutination test are in use:

(1) The "test tube" method in the State of Minnesota is done only by trained technicians at the laboratory of the State Live Stock Sanitary Board, University Farm, St. Paul. Blood samples are collected by the veterinarian and sent to this laboratory for the test.

(2) The "plate test" during the last few years has been done in the field by veterinarians specially trained and instructed in the application of this method.

Both tests involve similar principles and differ only in the method of applying the agglutination blood test. The plate test has the advantage of saving two days in obtaining results. Either test, if properly conducted and interpreted is satisfactory.

One of the principal factors limiting progress in the control and eradication of this disease is a lack of faith on the part of many cattle owners in the re- sults of the agglutination blood test. When this test is thoroughly understood, properly conducted, and correctly interpreted, it is an invaluable aid in the recognition and control of this disease and has been found to be as reliable as the tuberculin test.

\section{PREVENTION AND CONTROL}

The most successful method of treating contagious abortion is to prevent its spread. Various drugs have been used for its prevention and treatment, and although the results obtained vary considerably, none has proved of value. There is yet no reliable cure for Bang's disease.

\section{Isolation Important in Control}

The most active source of spread of this disease is the recent aborter. Sometimes a cow may calve normally and still scatter the abortion germs with the fetal and uterine fluids. It is, therefore, very important that animals be kept apart from the herd at the time of calving. Usually the germs disappear from the uterus in a few weeks, but sometimes they may be found in the uterus for a much longer time. The longer isolation can be continued, up to 30 days, the safer, but if this period is not practicable on the farm, all animals that have recently calved should be classed as infectec. and kept apart until all discharges cease.

Cleaning and carefully disinfecting the parturition stall are important. All infected material and bedding soiled. by discharges should be burned.

The bull should be kept apart from the herd, and breeding should be only on neutral ground, that is, ground not used by other cattle. After breeding, 
cows should be confined in stanchions where there is little danger of licking themselves or being licked by other cnimals. It is an excellent precaution to wash with soap and water the back parts of the cow which has been bred before allowing her to associate with cther animals. It is always advisable to keep her confined until the heat period passes.

It has been stated that many cows give off the germs of abortion in their milk. This is true of animals that have never aborted. Milk, therefore, should be considered an infective agent and carefully kept from contaminating the food of heifers or cows. Milk does not seem to be infective to young calves. Infection can take place through the teat canal although this is probably an unusual channel. Care must, however, be taken to have the hands clean and the suction cups of the machine disinfected before the milking of each animal.

These precautions do not eliminate all the possible sources of infection, but they dispose of certain of the most active sources and go to make up good stable sanitation, which should be practiced by every breeder whether or not his herd is infected with Brucellosis.

\section{Vaccination}

Various vaccines and serums are on the market for the prevention and cintrol of Bang's disease. Many experiments have been conducted at Univirsity Farm to determine, if possible, the actual value of these agents. As a result of these experiments, the following conclusions have been reached:

1. The living vaccine produces some irimunity to invasion of the placenta by Brucella abortus. The degree of immunity varies according to the individual, and the variations are marked.

2. Abortions occur in animals that have been treated with vaccines. It is true that living vaccines will reduce the abortion rate but not always to the desirable minimum.

Experiments conducted by the Federal Bureau of Animal Industry, Washington, D.C., with calf vaccination have yielded interesting results. This plan of vaccination provides that calves shall be tested by the agglutination method for the presence of Bang's disease and, if negative, shall be injected with a living vaccine of reduced virulence when the calves are between four and eight months old. The vaccinated calves are again tested when they reach the breeding age. If they are positive to the agglutination test at this time, they should be eliminated from the herd. Adult animals or animals positive to the agglutination test are not vaccinated. It is thought that in this way sufficient resistance can be given to the vaccinated calves so that they will be able successfully to resist infection in badly diseased herds. If the plan is successful, the positives will gradually be eliminated as they become unprofitable, and a completely negative herd will result. This vaccination method is still in the experimental stage. Results of its use will be watched with interest to determine accurately its value in Bang's disease control.

If a breeder desires his herd vaccinated, his veterinarian can obtain a permit for the use of vaccines by applying to the office of the Minnesota Live Stock Sanitary Board, State Office Building, St. Paul, Minnesota.

A breeder usually can not expect to eradicate the disease from his farm if 
he employs living vaccines. It should be borne clearly in mind that the disease is kept alive on the farms where living vaccines are used.

\section{Maintain Disease-Free Herds}

The only feasible method of controlling Bang's disease, in the light of present knowledge, is on the basis of the agglutination blood test and the maintenance of a herd free of the disease. Before outlining the methods that may be used in freeing herds from this disease, several important things should be pointed out:

1. Traffic in cattle indicates that it will not be long before all animals sold for dairy or breeding purposes will have to pass a negative blood test for Bang's disease. At present 46 states require a health certificate for this infection. California and Colorado are the only states not requiring a negative agglutination test for Bang's disease as a requirement for entrance.

2. Although the public health aspects of undulant fever in man, in our judgment, are not of primary importance, nevertheless they cannot be ignored. Consumers of raw milk, butter, and cheese are already demanding that these products come from animals free from Bang's disease or contagious abortion.

3. Herd owners should fully understand that even if Bang's disease is entirely eliminated from the herds, some abortions may occur. The Bang organism is responsible for approximately 85 per cent of abortions, but occasionally abortions occur in any medium-sized herd. Sterility may also occur in herds free of Bang's disease. The number of abortions and sterile cows in most herds, however, is ma- terially reduced when this disease is eliminated.

During the summer of 1934, because of extraordinary drouth conditions, several million dollars were set aside by the AAA to provide indemnity for cattle slaughtered because of infection with Bang's disease. This was a cattle reduction program. A Federal Bang's disease project was set up in many states. One of the first siates to take advantage of the Federal indemnity was Minnesota. Already many cattle owners had taken advantage of the plans offered by the State Live Stock Sanitary Board to free their herds of Bang's disease by means of the agglutination test. No indemnity had been available. These owners, as well as many others, were ready to take advantage of any indemnity provided. This project started, as stated above, on a cattle reduction basis. It has now become a disease control project and is officially known as "The FederalState Bang's Disease Program."

According to the latest figures available Minnesota has 3,317,867 cattle represented in 198,033 herds. Since the Federal-State Bang's Disease Program has been in operation the following work has been completed:

A total of 870,448 animals have been tested at least once.

A total of 58,473 herds have been tested at least once.

A total of 537,677 or 61.8 per cent of the animals have been retested.

Retesting of 37,076 or 63.4 per cent of the herds has been completed.

On the first test, a total of 99,629 or 11.4 per cent of the animals were positive.

On the first retest, positive animals numbered 20,720 or 3.9 per cent of all the animals. 
Table 1. Distribution of Bang's Disease Control Work in Minnesota According to Counties

\begin{tabular}{|c|c|c|c|c|c|c|c|}
\hline Counties & $\begin{array}{l}\text { No. herds } \\
\text { in counties }\end{array}$ & $\begin{array}{c}\text { No. herds } \\
\text { tested } f\end{array}$ & $\begin{array}{l}\text { Per cent } \\
\text { tested }\end{array}$ & Counties & $\begin{array}{l}\text { No. herds } \\
\text { in counties }\end{array}$ & $\begin{array}{l}\text { No. herds } \\
\text { tested } \uparrow\end{array}$ & $\begin{array}{l}\text { Per cent } \\
\text { tested }\end{array}$ \\
\hline 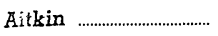 & 2653 & 1669 & 62.9 & Marshall ......................... & 2765 & 890 & 32.1 \\
\hline 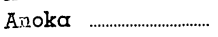 & 1676 & 483 & 28.8 & Martin & 2535 & 472 & 18.6 \\
\hline 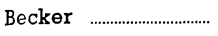 & 3146 & 1072 & 34.1 & Meeker & 2609 & 400 & 15.3 \\
\hline Beltrami & 2271 & 1453 & 64.0 & Mille Lacs ....................... & 2527 & 808 & 31.9 \\
\hline 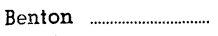 & 1725 & 708 & 41.0 & 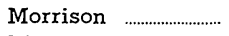 & 3582 & 1042 & 29.1 \\
\hline 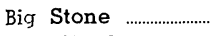 & 1243 & 347 & 27.9 & Mower ................................ & 2657 & 766 & 28.8 \\
\hline Blue Earth & 3204 & 593 & 18.5 & 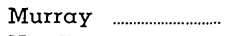 & 2065 & 575 & 27.8 \\
\hline Brown & 2173 & 446 & 20.5 & Nicollet ............................ & 1533 & 309 & 20.1 \\
\hline Carlton & 2374 & 1647 & 69.3 & 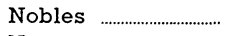 & 2330 & 365 & 15.6 \\
\hline 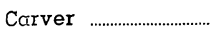 & 2085 & 54 & 2.6 & Norman ............................. & 2080 & 964 & 46.3 \\
\hline Caiss & 2234 & 1277 & 57.1 & Olmsted & 2593 & 717 & 27.6 \\
\hline Chippewa & 1849 & 530 & 28.6 & 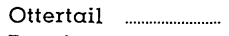 & 6980 & 1323 & 18.9 \\
\hline 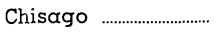 & 2070 & 586 & 28.3 & Pennington ..................... & 1157 & 1303 & $\ldots \ldots \ldots$ \\
\hline Clay & 2103 & 1098 & 52.2 & Pine & 3319 & 1456 & 43.8 \\
\hline Clearwater & 1477 & 796 & 53.8 & Pipestone & 1405 & 84 & 5.9 \\
\hline 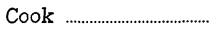 & 130 & 7 & 5.3 & Polk & 4182 & 1384 & 33.1 \\
\hline Cottonwood ................... & 2094 & 448 & 21.4 & Pope & 1950 & 416 & 21.3 \\
\hline Crow Wing ................. & 1969 & 1262 & 64.1 & Ramsey & 931 & 224 & 24.1 \\
\hline Dakota & 2482 & 480 & 19.3 & 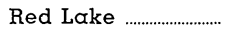 & 983 & 964 & 98.1 \\
\hline Dodge & 1856 & 293 & 15.8 & 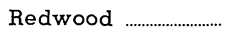 & 2736 & 289 & 10.5 \\
\hline Douglas & 2614 & 423 & 16.2 & 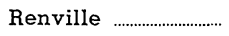 & 3305 & 228 & 6.8 \\
\hline Faribault & 2575 & 629 & 24.4 & Rice & 2391 & 457 & 19.1 \\
\hline Fillmore & 3363 & 1131 & 33.6 & Rock & 1425 & 102 & 7.1 \\
\hline Freeborn ........................... & 3169 & 469 & 14.8 & Rosequ & 2262 & 1428 & 63.1 \\
\hline 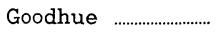 & 3276 & 519 & 15.8 & 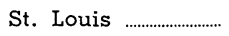 & 7658 & 2851 & 37.2 \\
\hline Grant & 1419 & 293 & 20.6 & Scott & 1740 & 281 & 16.1 \\
\hline Hennepin & 3700 & 548 & 14.8 & Sherburne & 1170 & 606 & 51.7 \\
\hline Houston & 1993 & 526 & 26.4 & 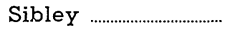 & 2324 & 354 & 15.2 \\
\hline 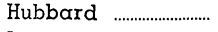 & 1420 & 1162 & 81.8 & Stearns & 4919 & 764 & 15.5 \\
\hline Isqnti & 2052 & 371 & 18.1 & Steele & 2022 & 166 & 8.2 \\
\hline Itasca & 2814 & 2072 & 73.6 & 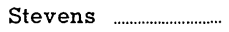 & 1315 & 236 & 17.9 \\
\hline Jackson & 2386 & 442 & 18.5 & Swift & 1969 & 134 & 6.8 \\
\hline Kanabec & 1775 & 815 & 45.9 & Todd & 3837 & 881 & 22.9 \\
\hline Kandiyohi & 2707 & 333 & 12.3 & Traverse & 1097 & 311 & 28.3 \\
\hline Kittson & 1550 & 747 & 48.1 & Wabasha & 1778 & 409 & 23.0 \\
\hline Koochiching .................... & 1282 & 498 & 38.8 & Wadena & 1583 & 931 & 58.8 \\
\hline Lac Qui Parle ...... & 2265 & 348 & 15.4 & Waseca & 1712 & 203 & 11.8 \\
\hline Lake & 411 & 223 & 54.2 & Washington .................. & 1881 & 525 & 27.9 \\
\hline Lake of the Woods & 643 & 341 & 53.0 & Watonwan & 1523 & 381 & 25.0 \\
\hline Le Sueur & 2282 & 515 & 22.6 & 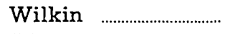 & 1267 & 552 & 43.5 \\
\hline Lincoln & 1644 & 295 & 17.9 & Winona & 2107 & 630 & 29.9 \\
\hline Lyon & 2047 & 499 & 24.3 & 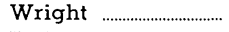 & 3811 & 671 & 17.6 \\
\hline 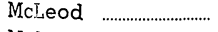 & 2576 & 297 & 11.5 & Yellow Medicine. & 2338 & 236 & 10.1 \\
\hline Mahnomen ..................... & 903 & 606 & 67.1 & & & & \\
\hline
\end{tabular}

* Determined by the last official tuberculin test.

$\dagger$ Determined by Minnesota Records of Testing to October 16, 1939.

A total of 35,830 or 61.3 per cent of the herds were negative on the first test.

On the first retest, 26,579 or 71.7 per cent of the herds were negative.

In order that this work could be carried out the Federal Government has spent $\$ 4,234,778.54$ and the State Government has spent $\$ 146,102.68$ in addition. These figures are of October 1 , 1939.

Table 1 shows the distribution according to counties for Bang's disease control work in Minnesota. 


\section{Minnesota Control Act}

The 1939 Legislature adopted Chapter 171 of the Laws of 1939 relating to the suppression of infectious diseases in the state. This act provides for the payment of indemnity for animals that are condemned because of Bang's disease. Under this act the maximum indemnity payment that can be made is $\$ 15$ for a grade female and $\$ 30$ for a purebred animal. It is further provided that when the payments are made jointly, as they have been in this state by the Federal and State Governments, the maximum amount cannot exceed the above figures.

For example, if an owner has an animal reacting to the agglutination test for Bang's disease, it is condemned, tagged, and branded by an official veterinarian of the State or Federal Government. The animal is appraised, let us say at $\$ 60$. It is sent to slaughter at an establishment having Federal meat inspection service. It brings on the market $\$ 40$. This salvage value is returned to the owner. In addition he will receive $\$ 15$ paid jointly by the Federal and State Governments, $\$ 7.50$ each. In other words, he receives $\$ 55$ for the animal. Let us suppose that another animal is appraised at $\$ 55$, and this individual has a net salvage value of $\$ 45$. The owner will receive jointly from the Federal and State Governments $\$ 10$ in addition, as the amount received cannot exceed the appraised value of the animal.

Several counties have been circulating petitions for area work. Five counties, Red Lake, Pennington, Hubbard, Beltrami, and Itasca, have their petitions completed, and hearings have been held. Testing started in Red Lake county early in November, 1939.
The work on Bang's disease control under the Federal-State plan is not restricted to area work. An agreement entered in jointly by the owner, the Minnesota State Live Stock Sanitary Board, and the Bureau of Animal In-. dustry of the United States Department of Agriculture provides for the testing of herds of cattle for the control and elimination of Bang's disease and for Bang's disease-free accredited herds. Bang's disease-free accredited. herds are herds in which no evidence of Bang's disease has been found in three blood tests at least six months apart of all cattle in the herd six months or over. Bang's disease-free accredited herds follow the work which has been done in this state since 1928 . Accredited herds for Bang's disease are copied in part from accredited herds for tuberculosis. Since Minnesota is now a tuberculosis-free modified accredited area, accredited herds for tuberculosis have not received much attention. Bang's disease is going through stages in its control similar to that of bovine tuberculosis.

The advantages to cattle owners who employ these methods of freeing their herds of Bang's disease are obvious. They are enabled to free their herds of diseased animals with the minimum of expense. The work of testing is carried out either in the laboratory of the State Live Stock Sanitary Board at University Farm or in the field by accredited veterinarians using antigens prepared by the United States Bureau of Animal Industry. Applications for contracts can be made either to the office of the State Live Stock Sanitary Board, State Office Building, St. Paul, Minnesota, or to the Bureau of Animal Industry, 1047 Post Office Building, Si. Paul, Minnesota. It is also probable 
that the local veterinarian or county agent will have a supply of these contracts on hand.

\section{Care of Pregnant Cows and Newborn Calves}

The proper handling of cows during advanced pregnancy is an important part in the general campaign against abortion. Place the animal in a clean disinfected box-stall. It should be kept clearly in mind that thorough cleansing is worth as much as disinfection, if not more.

When the calf is born, rub it dry with a clean cloth. Disinfect the stump of the navel cord with a 1 to 1,000 corrosive sublimate solution (tablets of this material may be purchased at any drug store) or tincture of iodine. Both of these are violent poisons. Place the solution in a tumbler, stand the calf on its feet, and immerse the stump in a tumbler of disinfectant. Keep it submerged from 15 to 30 seconds. The stump may then be dusted with an antiseptic powder composed of equal parts of boric acid and powdered alum.

Calves should be separated from their dams at birth and allowed to nurse only a very limited time at frequent intervals. Calves should get colostrum (first milk), which has certain properties that aid in protecting the newborn calf from various diseases.

Cows with retained afterbirth should be kept separate from the rest of the herd, and the udder should be carefully cleaned before the calf is permitted to nurse. Retained afterbirth is accompanied by dischiarges that stain the udder and, if not carefully watched, may cause scours in the calf. Milk from the cows with retained afterbirth, if mixed with other milk being fed to calves, may be responsible for causing a sudden outbreak of scours during which many of the animals will become ill at or near the same time.

Researches have shown that most newborn calves do not become actively infected with Brucella abortus from milk. The organisms may, however, locate in the lymph glands in the region of the throat where they remain for a few weeks.

\section{Treatment of Diseased Animals}

No attempt should be made by the layman to irrigate or disinfect the uterus (womb). Not only is it impossible to disinfect the cavity of the uterus, but it is also dangerous because the lining is easily injured and, at times, the walls of the uterus may be ruptured. Rupture, or severe injury, to the lining and walls of the uterus reduces the fertility of the animal or renders it a permanent nonbreeder. In some instances death follows in a short time. The vagina only should be irrigated, with a saline solution (a tablespoonful of common salt to a gallon of water).

Coal-tar disinfectants should not be employed as douches for the genital tract of cattle. The apparatus used in douching aborting cows should not be used around Bang-abortion-free cattle. The vagina can be douched by the use of a soft rubber tube one-half inch in diameter, one end of which is introduced into the vagina, the other end being attached to a funnel into which the solution is poured. The tube is then elevated so that the fluid will gravitate into the vagina. It is not necessary to siphon the fluid off. The cow that has recently aborted or has failed to expel the fetal membranes 
should be isolated and not permitted to mingle with other cattle until all discharges have ceased. Irrigation should be repeated daily for 10 days and then twice a week until there is no further evidence of discharge. If the fetal membranes are retained early treatments are necessary to maintain the health of the cow and to prevent the development of diseased conditions which may seriously interfere with her ability to get in calf again. Successful handling of cows that fail to clean is very important and the advice or services of a veterinarian should be obtained early.

Heifers and cows in herds free from Bang's disease or in herds in which the control of Bang's disease by use of the blood test is being attempted, may abort from causes other than the Bang germ. They too, should be separated from all other cattle and not returned to the herd until it can be definitely determined by repeated agglutination tests that they are not affected with Bang's disease.

\section{Breeding Cows Aborting from Other Causes}

An animal that has aborted should not be rebred until her genital organs no longer give off unnatural discharges. A healthy condition usually can be restored with proper care although some animals will remain diseased even after the best treatment known has been applied. It is folly to breed a cow that has a discharge from the uterus. She will not only be unlikely to conceive, but she may also expose the bull to a virulent infection other than Bang's disease, thereby tending toward the spread of the disease in the herd. Furthermore, in case the cow does conceive, the fetus may be expelled while quite small, and in a short time the heat period will recur. Many abortions of this type are not noticed.

It is impossible to say how long a time is necessary for the genital organs to become healthy. In some animals, with the proper treatment, it may not be more than 30 to 60 days. In other animals it takes months of careful treatment. The advice and services of a competent veterinarian are necessary in cases that stubbornly refuse to respond to treatment.

\section{Treatment of the Sire}

Bulls as well as females must be regularly tested in the control of Bang's disease. In this way actively infected animals can be removed from the herd, and this source of spread of the disease can be eliminated. Infertility is not uncommonly induced in the female by bulls infected with pusforming bacteria and protozoa. Sires developing sudden or spontaneous inflammation of one or both testicles should be carefully examined for Bang's disease (fig. 10). Those with unnatural discharges from the sheath should not be mated.

\section{Treatment of Infertile Cows}

Sterility, temporary or permanent, is a frequent sequel to abortion and is often the result of retention of the afterbirth, cystic ovaries, or inflammation of the uterus. In cows that fail to clean, certain pus-forming organisms gain entrance to the genital passages where they cause temporary or permanent changes. In herds in which reduced fertility exists, there is a docrease in milk production as well as a 


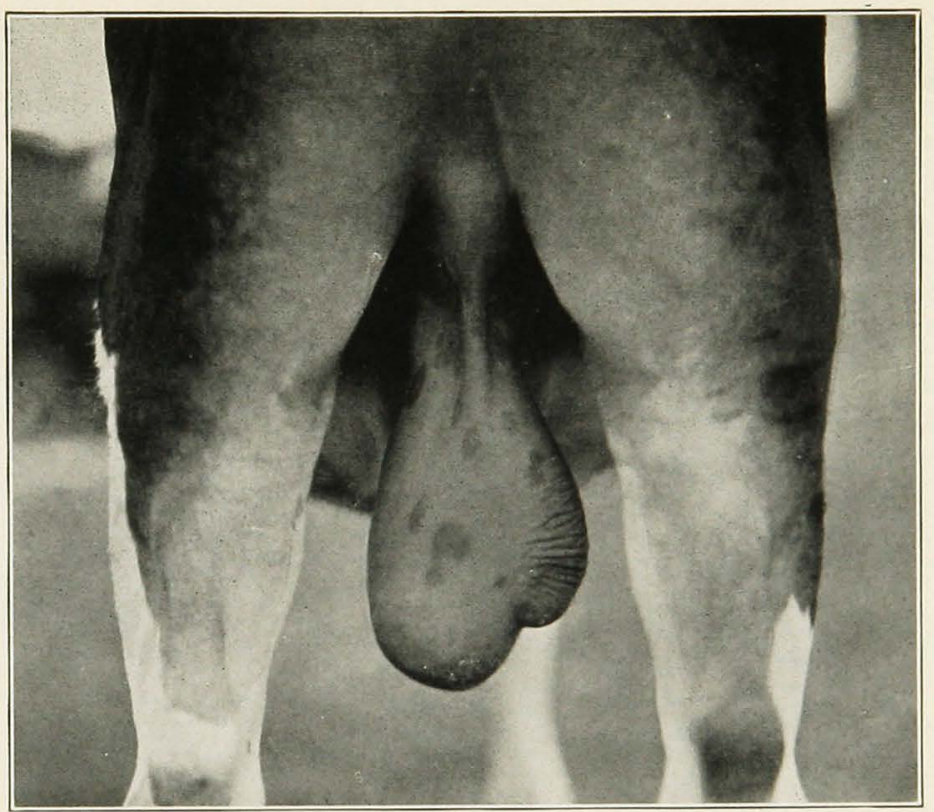

Fig. 10. Enlarged Left Testicle of Bull, Resulting from Inflammation

failure to produce calves. In many instances, sterile cows are bred every time they appear in heat. Frequent service not only aggravates the condition of the cow but also endangers the health of the sire as well. The treatment of sterility requires skill and should be attempted only by veterinarians. All cows that fail to breed should be examined; the incurable ones sent to slaughter; and the others treated and put into service again as soon as possible.

\section{Stable Sanitation}

Intelligent sanitation practices are an important part of the successful management of any livestock enterprise. Just as a matter of precaution it is advisable to clean thoroughly and disinfect the barns once or twice a year.
Disinfection, as it is frequently practiced, is of little or no value. The most common cause of failure is inadequate cleaning of the walls and floors that are to be disinfected. Because germs are so small and can be carried about in so many numerous ways, they may lodge in most remote parts of the stable and in places most difficult to reach with a disinfectant. Hence, the usual so-called "disinfection," which consists in scattering a strong-smelling substance about the barn, cannot be efficient. No disinfectant can destroy germs unless it comes in contact with them. Unless a thorough job of cleaning has been done before the disinfectant is applied, it cannot reach the germs and destroy them. If only part of the germs are destroyed, little real good has been accomplished, because in most cases only a very few live germs are necessary to produce 
disease if they are taken into the body. In other words, the most important part of the job is frequently slighted. A large part of the time and money spent in this operation should be used in cleaning the barn; otherwise the expense of disinfection is wasted.

The use of boiling hot water and soap or lye or washing powders with stiff scrub-brushes can hardly be overdone. Rotten woodwork and loose boards should be removed. Iron work should be repainted. It must be remembered, however, that paint usually contains lead and that lead, even in small amounts, is poisonous to animals, especially cattle. It is not advisable to use paint containing lead in or around the cow barn.

All manure and litter should either be burned or placed where animals cannot come in contact with it. Manure should be put on fields that are to be plowed in the near future or upon fields that are not to be used for pastures. Old straw stacks to which diseased animals have had access should be handled in the same way or fenced off to prevent healthy animals from coming in contact with them. If the floors of stables or sleeping sheds are of earth, it is advisable to remove 4 to 6 inches of the surface soil. This should be replaced with soil from an uncontaminated source or still better, install a new floor of concrete or some other permanent type.

Water troughs that are used by groups of animals should be carefully cleaned and disinfected.

COAL-TAR PRODUCTS-The coal-tar products, cresol, sheep dip, and numerous other similar products sold under trade names are among the most efficient disinfectants available. Their value depends upon the amount of the active material known as cresylic acid. Products that contain 50 per cent cf this active material are highly destructive to germs in a 3 to 4 per cent solution in water. These products are nonpoisonous to livestock in these dilutions and can be used freely in the disinfection of water tanks, mangers, and feed boxes. Two gallons of a coaltar disinfectant containing 50 per cent cresylic acid dissolved in 60 gallons of warm water are sufficient to disinfect 1,000 square feet of surface.

These products all have a strong, pungent odor which makes them undesirable for use in dairy barns because milk, which readily absorbs the odor, is rendered unsalable. This objection can be overcome largely by removing the milk from the barn as soon as it is taken from the animals. After a thorough disinfection of a dairy barn with any of the coal-tar products, it is usually necessary to guard against odors in the milk for approximately two weeks.

Chlorine Products-Various products that liberate chlorine, a gas, are commonly used in stable sanitation. They are undoubtedly of considerable value but are not so efficient in destroying germs in these places as are the coal-tar products. They readily lose their power to destroy germs when they are exposed to the air. The mistake of relying upon chlorine producis exposed to the air for varying lengths of time is common. Chloride of lime is the one most frequently used. Its valve as a disinfecting agent is unquestioned, but it is probably overrated by many persons because it is a powerful deodorant.

The value and economy of the work will depend in a great measure upon 
the method of applying the disinfectarit. Economy requires that the disinfccting solution be applied rapidly. Eniciency requires not only that it cover the entire surface, but that sufficient force be used to drive the solution into all cracks and crevices. The best method of applying a disinfectant is a stiong spray pump equipped with a hose and spray nozzle.

WHITEWASHING-Whitewashing is advisable in many stables because it makes the interior brighter and lighter. The lime wash should be applied only after the barn has been made scrupulously clean and disinfected. The addition of chloride of lime, 8 ounces to each gallon of whitewash, will increase its disinfecting properties. Whitewash is best applied with a spray pump such as is used in spraying orchards. The solution may then be forced into all the cracks and crevices of the barn with little difficulty.

\section{ABORTIONS IN A BANG'S DISEASE-FREE HERD}

One or more abortions occurring in well-managed herds and in which testing has been regularly performed are not uncommon. Naturally the owners feel that Bang's disease germs have again found their way into their herds. Aburtions taking place in cows or heilers that are five to seven months in call are especially alarming. But again one must not forget that 15 per cent of all abortions in cattle are caused by faciors other than Brucella abortus. Once Bang's disease is brought under conirol the abortions caused by either unknown or known agents will become of passing or temporary importance onl:. Non-specific diseases causing abo:tions in cattle, especially those cauied by bacteria or germs, are self- limiting. The abortions due to causes in which bacteria play no part are less significant and may to a large extent be prevented by careful herd management, with special emphasis being placed upon the feeding problem.

\section{THE PROBLEM OF TRICH- OMONIASIS}

Trichomoniasis, a term applied to a disease of the breeding organs of cattle, was first reported in this country in 1932. Since the time of that announcement, the disease has been recognized in many states, including Minnesota. Scientific as well as popular articles on various phases of this subject have been numerous. These writings combined with actual experiences on the part of veterinarians and, up to the present time, the breeders of purebred cattle have aroused much speculation as to the real significance of this disease in breeding cattle. The causative organism, a protozoon (small form of animal life), is apparently capable of living for long periods of time in the reproductive organs of both males and females. The infection spreads mainly by the act of breeding. Acute attacks in the sire are characterized by swelling of the sheath and refusal to breed.

After the initial attack has subsided, the bull will again perform service in a normal manner and in this way spread the disease. Females affected with the disease may develop inflammatory conditions of the reproductive tract, particularly the vagina and uterus. This may cause a delay in getting in calf or in the advent of successful fertilization result in the death of the fetus, which in most cases is expelled. Again, the fetus may die and be retained within the uterus indefinitely. 
Such cases may terminate in complete or incurable sterility. Reduced fertility becomes an acute problem, particularly in heifers, as the presence of infection in animals of this age seriously delays successful pregnancy.

Knowledge thus far gained in actual experience with the disease leads us to believe that the infection is self-limiting. If this supposition is true, methods of control and eradication will be much less intricate and, therefore, more effective. We wish to emphasize again that Brucellosis is responsible for 85 per cent of all abortions in cattle and that an occasional abortion in cattle negative to this disease should not be regarded as unusual. All abortions should be regarded as infectious until otherwise determined. Isolation of the aborting animal with repeated blood testing should be a regular procedure. This should be a common practice regardless of whether the abortion is due to Brucella abortus or organisms other than the Bang germ or in those cases where bacteria are in no way involved.

\section{BRUCELLOSIS OF SWINE}

The abortion germ of swine was isolated from an aborted swine fetus in California in 1914. Since this date, the disease has been reported in most of the states where swine raising is a major industry. Numerous outbreaks have been reported in Minnesota, and the germ, Brucella suis, has been isolated from distinct cases of this disease. There seem to be more affected animals and herds each year. Researches indicate that abortion in swine may, as in other animals, be due to several different organisms. However, the germ, Brucella suis, is the one most often found. This organism is very similar to Brucella abortus, the germ of cattle abortion, and the disease in swine closely resembles that of cattle.

Experiments have shown that the organism is contained in the dead aborted pigs, afterbirths, uterine discharges, and milk of infected sows. Hogs become infected by eating materials containing the germs, such as bedding, afterbirths, and milk. As in the case of cattle, a sow may give birth to healthy pigs and discharge the living and virulent germs at the time of and following parturition. The blood tests will show whether an animal is infected. The boar may develop the infection and become a carrier of the disease. The testicles when diseased become greatly enlarged, and Brucella suis may be isolated from the testicles.

The germs may become localized in the udders of infected sows, and in this way the sows may be carriers of the infection. Sterility may follow abortion although it is not so commonly reported as in cattle. Prevention and control measures for this disease are similar to those outlined for the disease in cattle. Swine breeders are urged to employ the blood test as a control measure.

\section{BRUCELLOSIS OF SHEEP}

The prevalence and importance of Brucellosis among sheep is unknown although the disease in sheep has long been recognized. Very little attention has been given to this affection which now, on account of the development of the sheep industry, becomes a problem of considerable economic importance. Abortion in sheep may be caused by Brucella abortus, but the most corr:- 
mon cause is a vibrio or $\mathrm{S}$-shaped germ, Tibrio fetus, which was first described in English investigators. This organism has been found to be one of the causes of abortion in sheep in Minnesota. The employment of the agglutination blood test on large numbers of animals will produce valuable information in detormining the extent of Bang's disease ii these animals.

While diseases of the genital organs are not so numerous in sheep as in cattle, they are fairly common and of vast importance. Reports of the presence of abortion in sheep are occasionally received from various sections of the state, but as yet no extensive investigations have been made. The symptoms, treatment, and control of this disease in sheep are similar to those for cattle. Abortion in sheep cannot be controlled by means of the agglutination test when caused by $\mathrm{Vi}$ brio fetus, but the agglutination test is a satisfactory method of controlling the disease when caused by Brucella abortus. Ewes, having aborted as the result of infection with Vibrio fetus, other germs, or unknown causes, should be separated from all other animals and not returned until all unnatural discharges have ceased. Certain investigators are of the opinion that the water supply is one of the chief ways in which the infection spreads. This is an additional reason why sheep should be provided with pure drinking water.

\section{BRUCELLOSIS OF HORSES}

Horses sometimes give positive reactions to the blood test for Bang's dis ase. Many horses have been tested in connection with the Federal-State Barig's disease program. Table 2 gives the results of these tests.
The animals reported in this table were horses which as a rule were not infected with fistula or poll evil. In order to get some evidence as to whether Brucellosis of horses has any relation to Brucellosis of cattle, data concerning infected bovine herds in which horses have been tested have been studied. The results of this study are given in table 3 .

It has been known for a long time that both fistula and poll evil of horses were associated with infection with Brucella abortus. These infected areas on the animal are very sore and sensitive. Later they may open, form a running sore, and very large quantities of pus may escape. It is usually advisable to have a veterinarian operate on such cases where the condition spreads far into the surrounding tissues.

Little information is available regarding the group of horses which have a high titer for Brucella abortus, and

Table 2. Report of Initial Test of Equine Blood for Bang's Disease*

\begin{tabular}{|c|c|c|c|}
\hline $\begin{array}{l}\text { Agglutination } \\
\text { Titers }\end{array}$ & No. & $\begin{array}{l}\text { Per } \\
\text { cent }\end{array}$ & \\
\hline$----\cdots$ & 3559 & 56.3 & \multirow{8}{*}{$\begin{array}{c}2577 \\
\text { or } \\
40.8 \text { per } \\
\text { cent }\end{array}$} \\
\hline$I----$ & 324 & 5.1 & \\
\hline+---- & 1042 & 16.5 & \\
\hline $\mathrm{II}----$ & 11 & 0.17 & \\
\hline$+I--\cdots$ & 446 & 7.1 & \\
\hline$+\mathrm{II}---$ & 3 & 0.08 & \\
\hline++--- & 390 & 6.2 & \\
\hline$++\mathrm{I}--$ & 192 & 3.0 & \\
\hline$++\mathrm{II}--$ & 1 & 0.02 & \multirow{10}{*}{$\begin{array}{c}190 \\
\text { or } \\
2.9 \text { per } \\
\text { cent }\end{array}$} \\
\hline+++-- & 166 & 2.6 & \\
\hline$+++\mathrm{I}-$ & 32 & 0.5 & \\
\hline$+++\mathrm{II}-$ & 1 & 0.02 & \\
\hline$+t+t--$ & 41 & 0.6 & \\
\hline$++t+\mathrm{I}-$ & 16 & 0.25 & \\
\hline$+t+t+-$ & 30 & 0.5 & \\
\hline$+t+t+I$ & 10 & 0.16 & \\
\hline$+t+t+t$ & 60 & 0.9 & \\
\hline Total & 6326 & 100.0 & \\
\hline
\end{tabular}

Dilutions: 1-25, 1-50, 1-100, 1-250, $1-500$, and $1-1000$

* There were 1,570 farms represented in this initial list. 
Table 3. Study of Infected Bovine Herds on Farms Where Horses Have Been Tested

\begin{tabular}{|c|c|c|c|c|c|c|c|c|c|c|}
\hline & \multicolumn{3}{|c|}{ First Bovine Test } & \multicolumn{3}{|c|}{ Last Bovine Test } & \multicolumn{4}{|c|}{ Present Status of Herds } \\
\hline & כ结 & 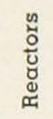 & $\begin{array}{l}\text { 茂 } \\
0 \\
0 \\
0 \\
0\end{array}$ & 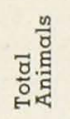 & 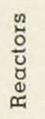 & 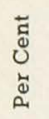 & $\begin{array}{l}0 \\
0 \\
0 \\
0 \\
0 \\
0 \\
z\end{array}$ & 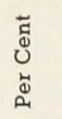 & 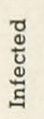 & $\begin{array}{c}\text { व̃ } \\
0 \\
0 \\
0 \\
0\end{array}$ \\
\hline $\begin{array}{l}\text { Farms where there were posi- } \\
\text { tive horses }\end{array}$ & 1449 & 431 & 29.7 & 1085 & 46 & 4.2 & 26 & 47.3 & 29 & 52.7 \\
\hline $\begin{array}{l}\text { Farms where all horses were } \\
\text { negative* }\end{array}$ & 1002 & 215 & 21.5 & 1043 & 5 & 0.5 & 41 & 74.5 & 14 & 25.5 \\
\hline
\end{tabular}

* 55 herds were included in this group.

which do not show evidence of fistula or poll evil. A few of these animals have been studied and Brucella abortus has been isolated from the feces of two individuals. We have also found a sternal osteomyelitis (sternal abscess) which was due to Brucella abortus (figs. 11 and 12).

We have not been able to isolate the Brucella organism from the circulating blood of horses. The work with these animals, however, is being continued.

The results of these studies indicate that Brucellosis of horses is of greater importance than has been generally appreciated, especially in its connection with Brucellosis of cattle. Abortions in horses have been reported as being due to the Bang germ. This organism, however, is not a cause of abortion in mares in Minnesota.

\section{RELATION OF BRUCELLOSIS TO HUMAN HEALTH}

It has been shown that undulant fever in man is caused by the same germ that causes Bang's disease in animals. There have been cases of undulant fever which apparently resulted from the ingestion of Bang's disease germs in raw milk.

Handling meat coming from animals infected with Bang's disease is also a means of transmitting undulant fever to man. This is particularly true in connection with carcasses of swine so infected. The disease is also spread to man by the handling of discharges, afterbirths, and aborted fetuses from infected animals, particularly swine. At present we would not classify undulant fever as a major public health problem. The dairyman and the breeder of meat-producing animals should consider the possibility of persons contracting undulant fever from Bang's disease germs in raw milk and other dairy products as well as in the flesh of infected animals, and particularly take into consideration the possible in-

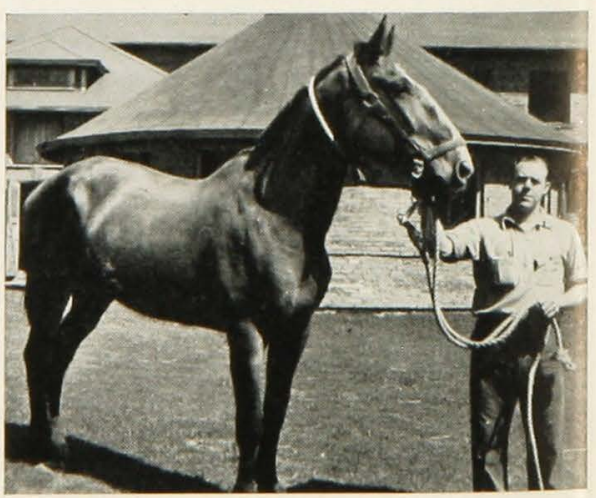

Fig. 11. Horse Affected with BrucelLosis Which Showed Sternal AbsCESS ON Autopsy 


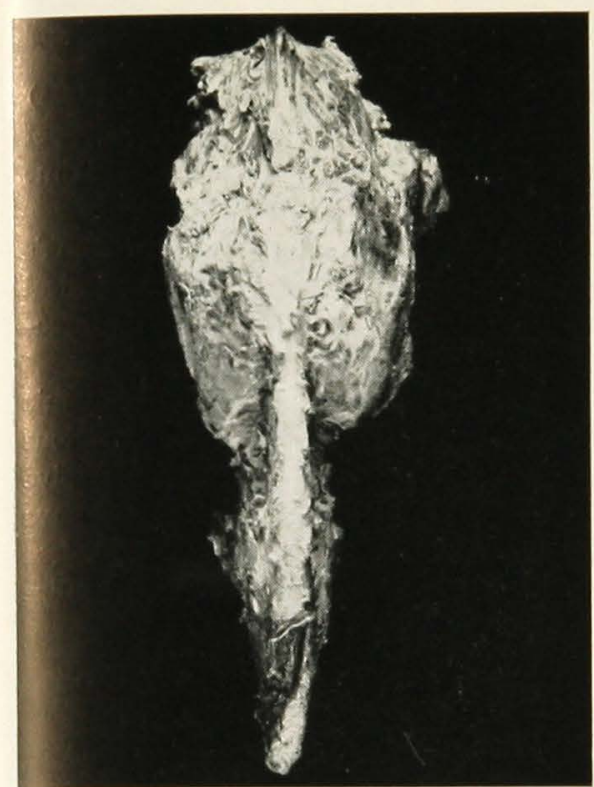

Fig. 12. Sternum of Horse Shown in Figure

11 Showing Marked EnLargement

(ABscess) Filled With Pus From

Which Brucella Abortus

WAS ISOLATED

fluence that this aspect of the disease may have on the market for their products.

\section{THE PREVENTION AND CONTROL OF BANG'S DISEASE}

1. All animals in the herd should be blood-tested to determine whether they are infected with Bang's disease.

2. All reactors to the test should be sold for immediate slaughter or isolated from the rest of the herd as they are potential spreaders of the disease.

3. A retest should be made of the herd not more than 30 to 60 days later. If new reactors are found they should be disposed of as stated above. Testing should be continued, preferably at 30 to 90 day intervals, until the herd has passed three entirely negative tests. These three negative tests should be at least three months apart. A single negative test is not conclusive proof of the absence of Bang's disease.

4. Additions made to the herd should be from herds tested and known to be free from Bang's disease. Negative animals from infected herds may be added but must be kept in quarantine for at least 60 days. If the animal is pregnant, she must be kept in quarantine for at least 20 days after calving. These animals, at the end of the quarantine period, should not be added to the herd unless their blood test is negative.

5. After each test and when the reacting animals have been marketed for slaughter, the premises should be cleaned and disinfected.

6. All females should be isolated at the time of calving or aborting. The afterbirth and aborted calf should be destroyed by burning or proper burial. These animals should be separated from the rest of the herd for two or three weeks or at least until all vaginal discharges cease. If a cow aborts, she should pass a negative test before she is returned to the herd. Although most abortions are due to Bang's disease, it is well to remember that all animais that abort do not have Bang's disease, also that all animals having a positive reaction to the test do not abort.

7. If calves born from reacting mothers are to be used as additions to the negative herd, they should be isolated for two to three weeks after their last feeding from the dam. Then they should be fed milk from negative animals and should also pass a negative blood test before they are added to the negative herd. 
8. Vaccines for the control of this disease are still in the experimental stage.

9. All milk and milk products used in negative herds should be from Bangfree cattle or should be pasteurized. Milk from positive animals is a dangerous source of spread of the disease.

10. Bulls in Bang-free herds should be used for service only on cattle that have been tested and found free from Bang's disease.

11. The control of Bang's disease by area testing at present is the most satisfactory method for the control of this infection.

\section{SUMMARY}

1. The agglutination test (blood test) is an invaluable aid in the diagnosis of Bang's disease and at the present time is the best method for its control.

2. The present Federal-State Bang's disease program is an economical method for ridding a herd of this infec.. tion.

3. Bang's disease from an economic standpoint is one of the most serious diseases affecting cattle. Progressive breeders and milk producers have learned that their herds must be free from this disease in order to realize the largest financial return. 